\title{
EDUCAÇÃO INCLUSIVA: UM ESTUDO DE CASO SOBRE O TRABALHO DOCENTE NA EDUCAÇÃO INFANTIL
}

\author{
INCLUSIVE EDUCATION: A CASE STUDY ABOUT TEACHER'S WORK IN \\ EARLY CHILDHOOD EDUCATION
}

\author{
Bruna Rafaela de BATISTA ${ }^{\mathrm{i}}$ \\ Luci Pastor MANZOLI ${ }^{\text {ii }}$
}

\begin{abstract}
RESUMO: A educação inclusiva é apoiada pela legislação brasileira, na qual se garante o acesso educacional de todos os educandos. Neste sentido, torna-se necessário observar desde o início, com a Educação Infantil, quais são as ações educativas que estão sendo realizadas para garantir o direito dos alunos PAEE. Deste modo, este estudo de caso teve como objetivo verificar com se dá o trabalho pedagógico com alunos PAEE em uma sala de aula comum na educação infantil. Participou do estudo uma professora da rede regular de ensino da etapa de educação infantil. A coleta dos dados ocorreu em uma escola de uma cidade do interior do estado de São Paulo. Para alcançar o objetivo proposto, a participante respondeu a um roteiro semiestruturado de questões por meio da técnica de entrevista que abordou dados de identificação e quatro eixos temáticos, sendo eles: Informações sobre o aluno PAEE; Trabalho docente; Escola e Família e Educação Inclusiva. Foram realizadas análises qualitativas por eixos temáticos com os dados obtidos por meio das entrevistas. Como resultado, constatou-se a realização de um trabalho pedagógico voltado à inclusão de sua aluna, assim como a necessidade de maior colaboração entre os profissionais da escola e maior participação por parte da família.
\end{abstract}

PALAVRAS-CHAVE: Educação inclusiva. Educação infantil. Prática pedagógica.

ABSTRACT: The inclusive education is supported by the Brazilian legislation ensuring educational access for all students. In this sense, it becomes required to observe from the beginning, with the early childhood education, what are the educational actions that are being carried out to guarantee the right of students PAEE. Thus, this study case aimed to verify how the pedagogical work works with students PAEE in a common an early childhood education classroom. A from the regular school system of early childhood education participated of the study. Data collection occurred in a school in a city in the state of São Paulo. To achieve the proposed objective, the participant answered a half-structured question set through interview technique that addressed identification data and four themes, namely: Information about the student PAEE; Teaching work; School and Family and Inclusive Education. Qualitative analysis by themes with data obtained through interviews were conducted. As a result, there was the realization of a pedagogic work aimed to include her student as well as the need for greater collaboration among school professionals, and greater participation by the family.

KEYWORDS: Inclusive education. Early childhood education. Pedagogical practice. 


\section{Introdução}

A educação inclusiva tem sido uma temática discutida amplamente pela literatura (MAZOTA, 1982; 2003; ARAÚJO; OMOTE, 2005; OMOTE ET. AL., 2005; GOMES; BARBOSA, 2006; MENDES, 2006, 2010; GLAT, 2007; BRUNO, 2008; ROPOLI ET. AL., 2010; BUENO; MELETTI, 2011; CARNEIRO, 2012), sendo fundamentada pelo direito de educação a todos.

O direito à educação a todos está amparado desde a Declaração Universal dos Direitos Humanos Art. 26 (1948), e da Declaração de Salamanca (Conferência Mundial, 1994), que compreende a educação como um direito fundamental de todas as crianças, jovens e adultos, independentemente de suas idades, sexo, etnia, religião, condição socioeconômica ou deficiência.

Embora a educação inclusiva constitua-se de uma variedade de segmentos, este estudo, especificamente, busca discutir a educação de alunos Público-alvo da Educação Especial - PAEE ${ }^{1}$.

Dentre a legislação brasileira que aborda os direitos educativos dos alunos PAEE, pode-se destacar a Constituição Federal de 1988, que garante o direito de educação a todos, e em seu parágrafo I no artigo 206 estabelece a "igualdade de condições para o acesso e permanência na escola" (BRASIL, 1988). Posteriormente, a Lei n ${ }^{\circ}$ 9.394/96 de Diretrizes e Bases da Educação Nacional, em seu artigo 59, veio instituir que os sistemas de ensino assegurassem aos alunos com deficiência currículo, métodos, recursos e organização específicos para atender suas necessidades.

Em 2001, a Resolução CNE/CEB $n^{\circ}$ 02/2001 estabeleceu as Diretrizes Nacionais para a Educação Especial na Educação Básica, que representou um progresso na perspectiva da universalização do ensino e um marco à diversidade na educação brasileira. No seu artigo $2^{\circ}$, o documento traz que "os sistemas de ensino devem matricular todos os alunos, cabendo às escolas organizar-se para o atendimento aos educandos com necessidades educacionais especiais, assegurando as condições necessárias para uma educação de qualidade para todos" (BRASIL, 2001, p. 69).

Foi garantido também, em 2008, pela Política Nacional de Educação Especial na Perspectiva da Educação Inclusiva, que apresenta como objetivo: o acesso, a

${ }^{1} \mathrm{O}$ termo público-alvo da educação especial (PAEE), correspondente à seguinte população escolar (1) estudantes com deficiência, (2) transtornos globais do desenvolvimento e (3) altas habilidades ou superdotação, descrita pela Lei no 12.796 , de 4 de abril de 2013. 
participação e a aprendizagem dos alunos com deficiência, transtornos globais do desenvolvimento e altas habilidades/superdotação nas escolas regulares.

Baseando-se nesses documentos, que apresentam a preocupação com a inclusão das pessoas PAEE, torna-se necessário observar desde o início, com a Educação Infantil, quais são as ações educativas que estão sendo realizadas para garantir o direito dos alunos PAEE.

De acordo com a Lei de Diretrizes e Bases da Educação Nacional (1996), Seção II, Art. 29, caracteriza-se como Educação Infantil: “primeira etapa da educação básica, tem como finalidade o desenvolvimento integral da criança de até 5 (cinco) anos, em seus aspectos físico, psicológico, intelectual e social, complementando a ação da família e da comunidade" (BRASIL, 1996).

Para a Política Nacional de Educação Especial na Perspectiva da Educação Inclusiva (2008):

$\mathrm{O}$ acesso à educação tem início na educação infantil, na qual se desenvolvem as bases necessárias para a construção do conhecimento e desenvolvimento global do aluno. Nessa etapa, o lúdico, o acesso às formas diferenciadas de comunicação, a riqueza de estímulos nos aspectos físicos, emocionais, cognitivos, psicomotores e sociais e a convivência com as diferenças favorecem as relações interpessoais, o respeito e a valorização da criança. (BRASIL, 2008, P.12)

A importância dessa etapa de ensino para o desenvolvimento dos alunos PAEE é abordada por vários estudos (OLIVEIRA; FERREIRA, 1986; CAVICCHIA, 1993; STRENZEL, 2001; DE VITTA; SANCHEZ; PEREZ, 2000; DE VITTA; EMMEL, 2004; DE VITTA; SILVA; MORAES, 2004; BISCEGLI et. al., 2007; BERSCH; MACHADO, 2007; DE VITTA; DE VITTA; MONTEIRO, 2010; MENDES, 2010; CARNEIRO, 2012.

Segundo Bersch e Machado (2007), a educação infantil permite que a criança com deficiência vivencie as mesmas experiências que crianças de sua idade, como brincadeiras corporais, sensoriais, músicas, estórias, cores, tempo e espaço, formas e afeto.

Para Mendes (2010), os primeiros anos de vida de uma criança são considerados cada vez mais importantes, sendo essa fase crítica para o desenvolvimento da inteligência, personalidade, linguagem e socialização.

Ao se pensar em tais princípios, observa-se que um dos componentes fundamentais para o desenvolvimento educacional do aluno PAEE é a prática pedagógica. No entanto, alguns estudos têm demonstrado fragilidade a este respeito, 
frente a formação de professores (KUHLMANN JR., 1999; PALHARES; MARTINEZ, 1999; DE VITTA; EMMEL, 2004; BERSCH; MACHADO, 2007; DE VITTA, 2010; MENDES, 2010; CARNEIRO, 2012).

Para Carneiro (2012), “A prática pedagógica inclusiva deverá se constituir pela junção do conhecimento adquirido pelo professor ao longo de sua trajetória e da disponibilidade em buscar novas formas de fazer considerando a diversidade dos alunos e as suas características individuais" (p.88). De acordo com Gomes e Barbosa (2006) é necessário que o professor esteja sempre em constate formação, com o domínio de instrumentos e referenciais que promovam o progresso de suas práticas pedagógicas.

Considerando a importância da inclusão do aluno PAEE na Educação Infantil, assim como o trabalho pedagógico a ser realizado para o desenvolvimento destes alunos, este estudo tem como objetivo verificar com se dá o trabalho pedagógico com alunos PAEE em uma sala de aula comum na educação infantil.

\section{Método}

O presente estudo de caso faz parte da disciplina "Trabalho docente no contexto da inclusão escolar" do Programa de Pós-Graduação em Educação Escolar da FCL/Unesp de Araraquara.

De acordo com Triviños (1987, p. 133, grifo do autor), o estudo de caso "é uma categoria de pesquisa cujo objeto é uma unidade que se analisa aprofundadamente".

Perante o ponto de vista metodológico, este estudo é de natureza qualitativa, que segundo Ludke e André (1986) permite a análise e descrição dos dados de forma articulada, tendo o ambiente como fonte direta e o pesquisador como seu principal instrumento.

\section{Participante}

Participou deste estudo uma professora da rede regular de ensino, que atendia aos critérios: atuar como docente da educação infantil e ter matriculado em sua sala de aula aluno PAEE. 
Em relação aos aspectos de identificação, a professora tinha 37 anos de idade, com formação em Pedagogia, e especialização em Educação Especial. Atuava como professora há 12 anos na educação infantil na pré-escola e no ensino fundamental.

Tendo em vista assegurar o sigilo da identidade da participante, nesse estudo a mesma será identificada pela consoante P.

\section{Procedimento de coleta de dados}

A coleta de dados foi realizada por meio de um encontro em uma escola municipal de uma cidade do interior do estado de São Paulo. Neste encontro realizou-se a entrevista com a participante, que teve em média a duração de 20 minutos, sendo gravada em áudio e transcrita na íntegra, para posterior análise. Para Manzini (1990/1991), a entrevista como método de coleta de dados pode fazer emergir informações de forma mais livre e não condicionadas a uma padronização.

\section{Instrumento}

O instrumento utilizado para a coleta de dados foi um roteiro semiestruturado com 20 questões, que abordavam aspectos sobre a caracterização do participante, aluno PAEE, trabalho docente, família e escola e educação inclusiva. De acordo com Manzini (1990/1991), o roteiro de entrevista permite abordar o tema que se pretende investigar, por meio de perguntas principais e complementadas por outras inerentes no momento da entrevista.

\section{Procedimento de análise dos dados}

A análise das entrevistas foi de cunho qualitativo, por meio de trechos das falas orais. Os dados foram analisados mediante a leitura das entrevistas e organizadas em temas que se aproximavam do objetivo da pesquisa. Segundo Vilelas (2009), a análise por temáticas consiste em operações de desmembramento do texto em unidades, 
mediante reagrupamentos analógicos, visando descobrir os núcleos de sentidos que compõem uma comunicação.

\title{
Resultados e discussão
}

A partir da análise dos dados foram identificados quatro eixos temáticos, sendo eles: (a) Informações sobre o aluno PAEE; (b) Trabalho docente; (c) Escola e Família e (d) Educação Inclusiva.

\section{a) Informações sobre o aluno PAEE}

No primeiro bloco foram relatadas as informações sobre o aluno, como tipo de deficiência, suas especificidades, aprendizagem e interação.

Em relação ao tipo de deficiência do aluno, P. narrou que não há um diagnóstico fechado, tendo como suspeita a deficiência intelectual, como apresentado a seguir:

\begin{abstract}
Ainda não tem diagnóstico certo, a aluna tem convulsões, dificuldade na fala, mudanças de comportamentos agressivos, dificuldade para entender solicitações e pouca memória de conceitos já trabalhados, a suspeita é de deficiência intelectual. A aluna frequentou a sala de recursos no início, mas no ano passado a mãe não quis mais aceitar o atendimento, pois não acha que sua filha precise e não aceita as dificuldades e necessidades da aluna. $(P)$
\end{abstract}

Com o relato de P. nota-se que seria importante a continuidade da participação da aluna no atendimento educacional especializado (AEE) ${ }^{2}$, por meio da participação da sala de recursos multifuncionais $(\mathrm{SRM})^{3}$, que contribuiria na realização de um diagnóstico preciso e no trabalho de suas necessidades, tendo em vista esta fase educacional ser de suma importância para o desenvolvimento do aluno PAEE (BERSCH; MACHADO, 2007; MENDES, 2010).

\footnotetext{
${ }^{2}$ De acordo com o Decreto 7.611 de 17 de novembro de 2011, o atendimento educacional especializado é compreendido como o conjunto de atividades, recursos de acessibilidade e pedagógicos organizados institucional e continuamente, prestado das seguintes formas: complementar à formação dos estudantes com deficiência, transtornos globais do desenvolvimento, como apoio permanente e limitado no tempo e na frequência dos estudantes às salas de recursos multifuncionais; ou suplementar à formação de estudantes com altas habilidades ou superdotação.

${ }^{3} \mathrm{O}$ programa das SRM é destinado às escolas das redes estaduais e municipais de educação com intuito de promover ensino com qualidade para alunos PAEE. Esse programa é desenvolvido de forma complementar e suplementar à escolarização, sendo oferecido o atendimento educacional especializado no contraturno ao qual o aluno frequenta na escola comum (PASIAN; MENDES E CIA, 2014).
} 
No que diz respeito a informação de uma aluna com deficiência na turma, P. relatou ter o conhecimento ao receber a lista com os nomes dos alunos, visto conhecer a aluna dos anos anteriores, pois a mesma frequentava a escola desde a fase I. Ainda em seu relato, P. abordou que sua reação foi de insegurança, devido a ter 25 alunos, não possuir auxiliar de sala, e não ter recebido nenhuma orientação frente as especificidades da aluna. Mesmo tendo especialização em Educação Especial, nota-se pelo relato de P. que sua reação é justificada pelos fatores de quantidade de alunos, falta de auxilio, apoio e orientação, fatores esses que segundo De Vitta, Silva e Moraes (2004), deveriam ser priorizados na discussão da inclusão na educação infantil.

Frente a aprendizagem e a interação da aluna, P. diz não considerar satisfatória a aprendizagem, pois acredita que seria necessário o atendimento na SRM para minimizar suas necessidades educativas. Em relação a interação da aluna, P. avalia como boa apesar de alguns problemas de comportamentos (bater no amigo, jogar o material, entre outros). Para Carneiro (2012), a interação, a convivência entre pares, deve acontecer desde a educação infantil em um modelo inclusivo que implique na formação de novas gerações com concepções sem pré-conceitos sobre o outro.

\title{
b) Trabalho docente
}

Nesse eixo se aborda a percepção do "ser docente" da participante e de seu trabalho pedagógico frente a uma sala de aula inclusiva. Ao ser questionada sobre o que é ser professor, P. faz a seguinte narração:

\begin{abstract}
Além de uma profissão, acredito que para exercer essa função é necessário ter um dom, que você pode ter antes da prática do magistério ou desenvolver no exercício dela, caso contrário o profissional ficará extremamente frustrado e desistirá dessa carreira. Esse dom demanda muita paciência e respeito, é preciso acreditar no aluno, e pensar que devemos orientá-los para construção uma sociedade melhor e mais justa. (P.)
\end{abstract}

Observa-se que P. tem como concepção da profissão o ato de orientar seus alunos para a construção de uma sociedade mais justa atrelada ao "dom", que de acordo com Haguette (1991) é a ideia de vocação que implica chamamento, personalismo, dom, graça divina.

Quanto ao trabalho pedagógico, P. diz não realizar atividades diferentes com a aluna PAEE, trabalhando o mesmo conteúdo com todos. Entretanto, relata que são 
necessárias adaptações curriculares diárias, como por exemplo, da quantidade de uma atividade exigida, demonstrada por sua fala a seguir.

Eu dou a mesma atividade para todos, para a aluna eu só exijo menos quantidade, pois sei que ela não conseguirá fazer a tempo tudo, como por exemplo, eu peço (oralmente) para os alunos identificar na música todas as palavras que comecem com a letra B, e para ela eu dou o exemplo da letra para ela poder identificar, outro exemplo, é a identificação dos nomes dos amigos, ela geralmente identifica o próprio com uma certa dificuldade. (P.)

Perante o relato, nota-se que P. tem compreensão da importância de se trabalhar o mesmo conteúdo com a aluna, realizando adaptações necessárias para a execução das atividades. Carneiro (2012) aponta que ao receber um aluno com necessidades específicas, é necessário que o planejamento seja flexível de modo a oportunizar modificações efetivas, devendo esta flexibilização curricular incorporar toda a prática pedagógica do professor.

\section{(c) Escola e Família}

Quanto a atuação da gestão escolar e da família, P, em relação ao auxílio da escola para seu $\Theta$ trabalho, diz não ter contribuição dos demais agentes educativos, com explicitado em sua fala:

Não. Inclusive solicitei que se reduzisse o número de alunos na sala por ter uma inclusão, porém ela (Diretora) disse que como a mãe nega os atendimentos, a criança não é considerada como inclusão, $e$ justifica também que a demanda para vagas é grande e que ela precisa colocar nas salas o número máximo de alunos. $(P$.

A realização do atendimento educacional especializado é garantida perante a legislação brasileira. No entanto, a família tem o direito de escolha sobre a participação ou não de tal programa e, com o relato de $\mathrm{P}$, nota-se que o fato tem sido tomado como justificativa para a não realização de auxílios por parte da gestão escolar, como apoio, redução do número de alunos, que seriam favorecedores para o desenvolvimento do trabalho pedagógico. Segundo Sousa (2004), para que a educação inclusiva seja efetivada, é necessário o exercício de colaboração entre a gestão escolar e os demais profissionais da escola, objetivando eliminar as barreiras organizacionais que possam impedir a educação dos alunos PAEE. 
Já a respeito da família, observa-se o entrave de troca entre família/escola, justificado pela não aceitação das dificuldades e necessidades da aluna, que acaba por provocar a negação de orientações e informações que seriam fundamentais para o aprendizado da mesma, a seguir a fala de P:

Vejo a mãe diariamente, mas ela não aceita as dificuldades da filha, acha que ela é manhosa, não consegue perceber ou aceitar que sua filha precisa de um atendimento. Nas atividades de tarefa a mãe pede para a irmã da aluna fazer, e mesmo orientada por mim diversas vezes para ajudar a aluna, a mãe diz que não tem paciência. (P.)

Observa-se com esses dados que seria imprescindível um trabalho com a família em relação a aceitação das especificidades da aluna, assim como um trabalho de identificação (diagnóstico) efetivo por parte do sistema escolar. Tendo em vista a importância da família para o desenvolvimento da criança, Williams e Aiello (2004) abordam que a realização de programas de intervenção pode proporcionar empoderamento familiar, na aceitação e na busca de recursos necessários para o filho.

\section{(d) Educação inclusiva}

Finalizando, neste eixo a participante é questionada sobre a inclusão escolar, frente a classe comum como lugar ideal ou não para a aprendizagem do aluno PAEE e a inclusão de forma geral no ensino comum. A seguir os relatos:

Para as atividades de desenvolvimento de conceitos diários sim, porque ela está inserida num contexto de diversidade de possibilidades, porém acho necessário que algumas horas da semana a criança deva ter atendimentos individuais para enfatizar conceitos $e$ despertar habilidades.

(Inclusão de forma geral no ensino comum) Acho ótima, os alunos podem ver e vivenciar a diversidade da sociedade, podendo aprender mais e se tornarem mais solidários. ( $P$.)

Mediante as falas é possível verificar por parte de P. concordância quanto ao processo inclusivo dos alunos PAEE. Dado este que corrobora com o estudo de Sant'Ana (2005), que ao investigar as concepções de 10 professores e seis diretores de escolas públicas do Ensino Fundamental de uma cidade do interior paulista, sobre a inclusão escolar, obteve que o discurso da maioria dos participantes demonstra uma posição favorável à inclusão dos alunos PAEE. 


\section{Conclusão}

A proposta deste estudo de caso foi de apresentar com se dá o trabalho pedagógico com alunos PAEE em uma sala de aula comum na educação infantil, mediante o relato de uma professora da rede regular de ensino.

O estudo demonstrou que a professora desenvolve um trabalho pedagógico voltado à inclusão de sua aluna, e que se preocupa com o desenvolvimento da mesma, apontando várias vezes a importância do atendimento educacional especializado.

Os resultados apresentaram que se faz necessário uma maior colaboração entre os profissionais da escola, e maior participação por parte da família, para que a educação inclusiva seja verdadeiramente realizada.

Alguns indicativos apontados no estudo se referem ao desenvolvimento de apoios organizacionais, empoderamento familiar e reorganização nos processos de identificação (diagnóstico) do PAEE de forma mais efetiva.

Como limitação do estudo, apresenta-se que a quantidade de participantes não é capaz de sustentar a temática abordada, mas pode suscitar reflexões sobre o trabalho pedagógico na perspectiva da educação inclusiva, assim como a realização de novos estudos por inquietações provocadas.

\section{Referências}

BERSCH, R.; MACHADO, R. Conhecendo o aluno com deficiência física. In: SCHIRMER, C. R.; BROWNING, N.; BERSCH, R.; MACHADO, R. Atendimento educacional especializado: Deficiência física. SEESP/SEED/MEC. Brasília, 2007.

BISCEGLI, T. S. et al. Avaliação do estado nutricional e do desenvolvimento neuropsicomotor em crianças frequentadoras de creche. Rev. Paul. Pediatr., v.25, n.4, p.337-42, 2007.

BRUNO, M. M. G. A construção da escola inclusiva: uma análise das políticas públicas e da prática pedagógica no contexto da educação infantil. Ambiente Educação, v. 1, n. 2, p. $57,2008$.

BUENO, J. G. S.; MELETTI, S. M. F. Os indicadores educacionais como meio de avaliação das políticas de educação especial no Brasil - 2000/2009. In: BUENO, José Geraldo Silveira. Educação especial brasileira: 20 anos depois. São Paulo, EDUC, no prelo. 
BUENO, J. G. S.; MELETTI, S. M. F. Educação infantil e educação especial: uma análise dos indicadores educacionais brasileiros. Revista Contrapontos, Vol. 11 - n. 3 p. 278-287 / set-dez 2011.

BRASIL, Assembleia Nacional Constituinte. Constituição da República Federativa do Brasil. Brasília, DF: Senado Federal/Secretaria Especial de Editoração e Publicações, $1988 . \quad$ Disponível em: <http://www.planalto.gov.br/ccivil_03/Constituicao/Constituicao.htm>. Acesso em: 19 de abr. de 2016.

Congresso Nacional. Lei n. 9.394, de 20 de dezembro de 1996. Estabelece as diretrizes e bases da educação nacional. Diário Oficial da União n. 248, de 23/12/96 Seção I, p. 27833. Brasília, 1996. Disponível em: <http://www.planalto.gov.br/ccivil_03/Leis/L9394.htm>. Acesso em: 19 de abr. de 2016.

Presidência da República, Secretaria Especial dos Direitos Humanos. Declaração de Salamanca e linha de ação sobre necessidades educativas especiais. Brasília, DF: Coordenadoria Nacional para Integração da Pessoa Portadora de Deficiência - $\quad$ CORDE, $1997 . \quad$ Disponível em: <http://portal.mec.gov.br/seesp/arquivos/pdf/salamanca.pdf >. Acesso em: 19 de abr. de 2016.

Ministério da Educação. Resolução CNE/CEB no.2, de 11/09/2001. Institui Diretrizes Nacionais para a Educação Especial na Educação Básica. Brasília: 2001. Disponível em: <http://portal.mec.gov.br/cne/arquivos/pdf/CEB0201.pdf〉. Acesso em: 19 de abr. de 2016.

Ministério da Educação. Política Nacional de Educação Especial na perspectiva da educação Inclusiva. Brasília, DF, 2008. Disponível em: <http://peei.mec.gov.br/arquivos/politica_nacional_educacao_especial.pdf>. Acesso em: 19 de abr. de 2016.

Ministério da Educação. Decreto 7.611 de 17 de novembro de 2011. Dispõe sobre a educação especial, o atendimento educacional especializado e dá outras providências. Brasília, DF, 2011. Disponível em: <http://www.planalto.gov.br/ccivil_03/_ato2011-2014/2011/decreto/d7611.htm>. Acesso em: 27 de abr. de 2016.

Ministério da Educação. Lei 12.796, de 4 de abril de 2013. Altera a Lei $\mathrm{n}^{-}$9.394, de 20 de dezembro de 1996, que estabelece as diretrizes e bases da educação nacional, para dispor sobre a formação dos profissionais da educação e dar outras providências. Disponível em: < http://www.planalto.gov.br/ccivil_03/_ato20112014/2013/lei/112796.htm>. Acesso em: 19 de abr. de 2016.

CARNEIRO, R. U. C. Educação inclusiva na educação infantil. Práxis Educacional Vitória da Conquista, v. 8, n. 12, p. 81-95, jan./jun. 2012.

CAVICCHIA, D. C. O cotidiano da creche: um projeto pedagógico. São Paulo: Loyola, 1993.

DECLARAÇÃO MUNDIAL SOBRE EDUCAÇÃO PARA TODOS. Plano de ação 
para satisfazer as necessidades básicas de aprendizagem. Tailândia, 1990. Disponível em: <http://unesdoc.unesco.org/images/0008/000862/086291por.pdf >. Acesso em: 19 de abr. de 2016.

DE VITTA, F. C. F.; SANCHEZ, F. F.; PEREZ, R. R. M. Desenvolvimento motor infantil: aplicação de um programa de educação para berçaristas. Mimesis, Bauru, v. 21, n. 1, p. 101-118, 2000.

DE VITTA, F. C. F.; EMMEL, M. L. G. A dualidade cuidado x educação no cotidiano do berçário. Paidéia, Ribeirão Preto, v.14, n.28, p.177-189, 2004.

DE VITTA, F. C. F.; SILVA, K. L. P.; MORAES, M. C. A. F. Conceito sobre a educação da criança deficiente, de acordo com professores de educação infantil da cidade de Bauru. Rev. Bras. de Ed. Especial, Marília, v.10, n.1, p. 43 -58, 2004.

DE VITTA, F. C. F. A inclusão da criança com necessidades especiais na visão de berçaristas. Cadernos de Pesquisa, v.40, n.139, p.75-93, 2010.

DE VITTA, F.C.F.; DE VITTA, A.; MONTEIRO, A.S.R. Percepção de professores de educação infantil sobre a inclusão da criança com deficiência. Rev. Bras. Ed. Esp., Marília, v.16, n.3, p.415-428, Set.-Dez., 2010.

HAGUETTE, André. Educação: bico, vocação ou profissão?. Educação e Sociedade, $\mathrm{n}^{\circ} 38,1991$, p. 109-121.

GLAT, R. (Org.) Educação Inclusiva: cultura e cotidiano escolar. Rio de Janeiro: 7Letras, 2007.

GOMES, C.; BARBOSA, A. J. G. A inclusão escolar do portador de paralisia cerebral: atitudes de professores do ensino fundamental. Rev. Bras. Ed. Esp., Marília, v.12, n.1, p.85-100, 2006.

KUHLMANN JR., M. Educação infantil e currículo. In: FARIA, A.L.G., PALHARES, M.S. (Org.). Educação infantil pós- $\angle D B$ : rumos e desafios. São Carlos: Editora da UFSCar, 1999.

LÜDKE, M., ANDRÉ, M. E. D. A. Pesquisa em educação: abordagens qualitativas. São Paulo: EPU, 1986.

MANZINI, E. J. A entrevista na pesquisa social. Didática, São Paulo, v. 26/27, p. 149$158,1990 / 1991$.

MAZZOTA, M. J. S. Fundamentos de educação especial. São Paulo: Pioneira, 1982.

MAZZOTA, M. J. S. Educação do portador de deficiência no novo milênio: dilemas e perspectivas. Em S. Silva \& M. Vizim (Orgs.), Políticas públicas: educação, tecnologias e pessoas com deficiência (pp. 37-48). Campinas, SP: Mercado das Letras, Associação de Leitura do Brasil, 2003.

MENDES, E. G. A radicalização do debate sobre inclusão escolar no Brasil. Revista Brasileira de Educação, v. 11 n. 33 set./dez. 2006. 
MENDES, E. G. Inclusão marco zero: começando pelas creches. Araraquara, SP: Junqueira \& Marin, 2010.

OLIVEIRA, Z. M. R., FERREIRA, M. C. R. Propostas para o atendimento em creches no município de São Paulo: histórico de uma realidade. Cadernos de Pesquisa. São Paulo v. 56, p. 39-65, fev. 1986.

OMOTE, S. et. al. Mudança de atitudes sociais em relação à inclusão. Cadernos de Psicologia e Educação - Paideia, 15(32), 387-398, 2005.

PALHARES, M. S.; MARTINEZ, C. M. S. A educação infantil: uma questão para o debate. In: FARIA, A. L. G.; PALHARES, M. S. (Org.). Educação Infantil pós- $L D B$ : rumos e desafios. São Carlos, SP: Editora da UFSCar; 1999.

PASIAN, M. S.; MENDES, E. G.; CIA, F. Salas de recursos multifuncionais: Revisão de artigos científicos. Revista Eletrônica de Educação, v. 8, n. 3, p. 213-225, 2014.

ROPOLI, E. A. et. al. A educação especial na perspectiva da inclusão escolar: a escola comum inclusiva. Brasília: Ministério da Educação, Secretaria de Educação Especial; [Fortaleza]: Universidade Federal do Ceará, 2010.v. 1. (Coleção A Educação Especial na Perspectiva da Inclusão Escolar).

SANT'ANA, I. M. Educação inclusiva: concepções de professores e diretores. Psicol. estud. vol.10 no.2. Maringá May/Aug. 2005.

SOUSA, L. P. F. de. Orquestrar a gestão escolar para respostas educativas na diversidade. 2007, 113p. Dissertação (Mestrado em Educação) - Universidade do Estado do Rio de Janeiro. Faculdade de Educação. Rio de Janeiro.

STRENZEL, G. R. A contribuição das pesquisas dos programas de pós-graduação em educação: orientações pedagógicas para crianças de 0 a 3 anos em creches. In: 24 REUNIÃO ANUAL DA ANPEd, 2001, Caxambu.

TRIVIÑOS, A. N. S. (1987). Introdução à pesquisa em ciências sociais: A pesquisa qualitativa em educação. São Paulo, SP: Atlas.

VILELAS, J. Investigação - o Processo de Construção do Conhecimento. Lisboa: Edições Sílabo, 2009.

WILliAMS, L. C. A.; AIELLI, A. L. R. O emponderamento de famílias: O que é e como medi-lo. In: MENDES, E.G.; ALMEIDA, M.A.; WILLIAMS, L.C.A. (Orgs.). Avanços recentes e Educação Especial. São Carlos: EDUFSCAR, 2004.

\section{Como referenciar este artigo}

BATISTA, Bruna Rafaela de.; MANZOLI , Luci Pastor. Educação inclusiva: um estudo de caso sobre o trabalho docente na educação infantil. Revista Ibero-Americana de Estudos em Educação, v. 11, n. esp. 2, p.881-894, 2016. Disponível em: <https://dx.doi.org/10.21723/riaee.v11.esp2.p881-894>. E-ISSN: 1982-5587. 


\section{Sobre os autores}

${ }^{\text {i }}$ Mestranda em Educação Escolar. UNESP - Universidade Estadual Paulista. Faculdade de Ciências e Letras - Pós-graduação em Educação Escolar. Araraquara - SP - Brasil. 14800-901 bru_tifa@yahoo.com.br

ii UNESP - Universidade Estadual Paulista. Faculdade de Ciências e Letras - Pós-graduação em Educação Escolar. Araraquara - SP - Brasil. 14800-901 - ozilu@ fclar.unesp.br 